\title{
Reinforcing the vast difference between the outcomes of spontaneous versus induced miscarriages
}

\section{Laxmi Maru, Monica Verma*, Tazeen Khan}

Department of Obstetrics and Gynaecology, MGM Medical College, Indore, Madhya Pradesh, India

Received: 15 September 2016

Revised: 18 September 2016

Accepted: 08 October 2016

\section{*Correspondence:}

Dr. Monica Verma,

E-mail: mv27sep@gmail.com

Copyright: ( ) the author(s), publisher and licensee Medip Academy. This is an open-access article distributed under the terms of the Creative Commons Attribution Non-Commercial License, which permits unrestricted non-commercial use, distribution, and reproduction in any medium, provided the original work is properly cited.

\section{ABSTRACT}

Background: Information on incidence of spontaneous and induced abortion is crucial for identifying policy and programmatic needs aimed at reducing unintended pregnancies. In this study, we analyzed in detail the presentation, complications of abortions and procedure associated complications of spontaneous and induced miscarriages.

Methods: The study was prospectively conducted on 200 patients from IPD of MGM Medical College, Indore over a period of two years and under the guidance of population council of India. The patients were divided into 2 groups of 100 patients each under spontaneous and induced miscarriages.

Results: After matching the parity, age of mothers, gestational age at presentation and socioeconomic status the results were analyzed. $45 \%$ women presented with incomplete abortion followed by inevitable (20), missed (12) and complete abortion (19) in the spontaneous abortion group. In induced abortion group majority of women presented with failure of contraception, natural method use being the most common method of contraception. Young women preferred medical abortion while multiparous women went for surgical evacuation. Minor and tolerable side effects like mild bleeding pain nausea etc. were seen in medically supervised group of induced miscarriage. Major and life threatening complications were seen in the spontaneous abortion group like heavy bleeding, hypovolumic shock, septic abortion, foul smelling vaginal discharge, bowel injury and also one mortality was seen in the spontaneous abortion group.

Conclusions: While appreciable progress has been made in legalizing and improving MTP services, the unmet needs continue to grow. Efforts should be made to make safe abortion facilities available to majority of population. At the same time awareness should be spread so that seeking abortion does not become an alternative to contraception.

Keywords: Outcome, Planned miscarriage, Spontaneous miscarriage, Septic abortion

\section{INTRODUCTION}

More than 1.2 billion people live in India; approximately $26 \%$ (328 million) of whom are women of reproductive age (15-49). According to Sample Registration System data for 2012, women in India have an average of 2.4 births in their lifetime. ${ }^{1}$ This key indicator of reproductive health, known as the total fertility rate, has declined from 3.6 in 1991. Women living in urban areas have fewer children (1.8) than their rural counterparts (2.6). Reproductive outcomes vary widely throughout India, reflecting the social, demographic and economic diversity of its states and differential access to health services across the country.

Over the past decade, some key policy developments have contributed to improved availability, accessibility and safety of induced abortion services; these include revised regulations expanding services to primary health centers, the approval of medical abortion for terminating early pregnancies, and the promotion of manual vacuum aspiration as the preferred method for early surgical abortion. ${ }^{2}$ The impact of these efforts has been dampened by difficulties in implementation. The incidence of 
complications among women having unsafe abortions is poorly documented.

As we are losing more mothers due to illegal and septic abortion practices, government are now forming many rights to make abortion liberal. Through this study we are trying to address and evaluate gap in knowledge, attitude and practice regarding unmet needs of contraception in relation to unwanted pregnancies, induced abortion for various indications and associated complications with them.

\section{Aims and objectives}

- To study the incidence of spontaneous and induced abortions.

- To study etiology of spontaneous abortions and Induced abortions.

- To compare post abortion complications in cases of Spontaneous abortions v/s Induced abortions (Medical abortions, Manual vacuum aspiration, Dilation and Curettage), for the assessment of requirement of comprehensive abortion care at various health care sectors and areas.

- To evaluate KAP of women for different methods of family planning after spontaneous and induced abortions.

\section{METHODS}

The study was conducted on 200 patients selected from IPD of MGM Medical College, Indore, MP, India. The study was done over a period of two years. The patients were selected under following criteria after detailed history and examination. The study was undertaken under the guidance of Population council of India. After applying for the various inclusion and exclusion criteria, the women were divided into two groups. Group A consisted of women presenting with spontaneous abortion and group B women were offered medical termination of pregnancy by various methods. Both groups had a total of 100 patients.

\section{Inclusion criteria}

- Married women

- Good general health

- Older than the age of legal consent

- Presented with spontaneous abortion, threatened abortion, inevitable abortion or incomplete abortion

- Requesting legal termination of pregnancy

- Duration of pregnancy up to 20 weeks duration

- Single intrauterine pregnancy

\section{Exclusion criteria}

- Medical conditions contraindicating the use of mifepristone (e. g. adrenal disease)
- Medical conditions contraindicating the use of misoprostol (e. g. Hypertension, Mitral stenosis, bronchial asthma, glaucoma, sickle cell anemia, hypotension)

- Allergy to mifepristone or misoprostol

- A history or evidence of thromboembolism

- Liver disease or pruritus of pregnancy

- Previous surgery of uterine cervix

- Presence of an intrauterine device

- Suspected or proven ectopic pregnancy

\section{RESULTS}

Table 1 shows the demographic factors of the women included in the study. Women were divided in two groups whilst one that of women complaining of spontaneous abortion and the second that of women attending OPD for medical termination of pregnancy. Both groups had 100 women in each group. In group A $16 \%$ were <21 years of age and $62 \%$ were between 21 and 30 years of age. In group B $20 \%$ were $<21$ years of age and $70 \%$ were between 21 and 30 years of age. In both groups maximum cases belonged to the age group of 18-25 yrs. Below 21 years of age cases used mostly MTP kit as a method of medical termination but maximum cases of 2130 years preferred surgical evacuation as a method of choice. The $\mathrm{p}$ value was not significant being 0.618 , making the two groups comparable.

Table 1: Demographic factors.

\begin{tabular}{|c|c|c|c|c|}
\hline & & $\begin{array}{l}\text { Group A } \\
(\mathbf{n}=100)\end{array}$ & $\begin{array}{l}\text { Group B } \\
(\mathbf{n}=\mathbf{1 0 0})\end{array}$ & $\begin{array}{l}P \\
\text { value }\end{array}$ \\
\hline \multirow[t]{4}{*}{ Maternal age } & $<21$ & 16 & 20 & 0.618 \\
\hline & $21-25$ & 34 & 39 & \\
\hline & $26-30$ & 28 & 31 & \\
\hline & $>30$ & 22 & 10 & \\
\hline \multirow[t]{4}{*}{$\begin{array}{l}\text { Socioeconomic } \\
\text { status }\end{array}$} & $\begin{array}{l}\text { Upper } \\
\text { middle }\end{array}$ & 10 & 18 & 0.072 \\
\hline & $\begin{array}{l}\text { Lower } \\
\text { middle }\end{array}$ & 33 & 36 & \\
\hline & $\begin{array}{l}\text { Upper } \\
\text { lower }\end{array}$ & 37 & 34 & \\
\hline & Lower & 20 & 12 & \\
\hline \multirow[t]{4}{*}{ Parity } & Primi & 30 & 26 & 0.701 \\
\hline & $\mathrm{G} 2$ & 18 & 23 & \\
\hline & G3 & 28 & 37 & \\
\hline & $>/=\mathrm{G} 4$ & 24 & 14 & \\
\hline \multirow[t]{4}{*}{ Gestational age } & $\begin{array}{l}6-10 \\
\text { weeks }\end{array}$ & 33 & 37 & 0.223 \\
\hline & $\begin{array}{l}10-12 \\
\text { weeks }\end{array}$ & 38 & 31 & \\
\hline & $\begin{array}{l}12-14 \\
\text { weeks }\end{array}$ & 18 & 20 & \\
\hline & $\begin{array}{l}14-16 \\
\text { weeks }\end{array}$ & 11 & 12 & \\
\hline
\end{tabular}

The women were evaluated on the basis of socioeconomic status by modified Kuppuswamy scale. In group A $43 \%$ belonged to Middle class and $57 \%$ 
belonged to Lower class. In group B 54\% belonged to Middle class and $46 \%$ belonged to Lower class. In both the groups patients mainly belonged to Lower-middle and Upper-lower strata of socioeconomic class. This shows expansion and availability of healthcare facilities to all classes of society. It also shows greater awareness among women regarding medical termination of pregnancy.no woman in any group belong to the higher socioeconomic status. The $\mathrm{p}$ value in the two groups was 0.072 , not significant, groups comparable.

Table 2: Types of spontaneous abortions.

\begin{tabular}{|ll|}
\hline Causes & Group A $(\mathbf{n}=\mathbf{1 0 0})$ \\
\hline Incomplete abortion & 45 \\
\hline Threatened abortion & 4 \\
\hline Inevitable abortion & 20 \\
\hline Missed abortion & 12 \\
\hline Complete abortion & 19 \\
\hline Total & 100 \\
\hline
\end{tabular}

In the assessment of the parity status of the women Group A was $30 \%$ primi patients, $18 \%$ 2nd gravid (have one living child), $52 \%$ were $\geq 3^{\text {rd }}$ gravida (having $\geq 2$ child). In Group B 26\% were primi patients, $23 \%$ were 2 nd gravid (have one living child), $51 \%$ were $\geq 3^{\text {rd }}$ gravida (having $\geq 2$ child). In both groups maximum women were multigravidas ( $\mathrm{p}$ value $=0.701$, not significant).

\section{Table 3: Causes for Medical termination of pregnancy.}

\begin{tabular}{|ll|}
\hline Causes & Group B $(\mathrm{n}=100)$ \\
\hline Contraception failure & 51 \\
\hline Congenital anomaly of fetus & 27 \\
\hline Failure of sterilization & 10 \\
\hline Blighted ovum & 12 \\
\hline Total & 100 \\
\hline
\end{tabular}

According to the gestational age at presentation, in group A 33 cases were of gestational age 6-10 wks, 38 cases had 10-12 wks of gestational age and 18 cases had 12-14 wks of gestational age, 11 cases had gestational age of $>14$ wks. In group B 37 cases had gestational age of 6-10 wks, 31 cases had 10-12 wks of gestational age and 20 cases had 12-14 wks of gestational age, 12 cases had gestational age of $>14$ wks ( $p$ value $=0.223$ ).

Table 2 depicts the diagnosis at admission in the women belonging to the spontaneous abortion group. Out of 100 cases, 45 presented as incomplete abortion, 4 as threatened abortion, 20 as inevitable abortion, 12 as missed abortion and 19 with complete abortion. Maximum patients belonged to the incomplete abortion subgroup.

Table 3 illustrates the reasons with which the women in group B approached the OPD for termination of pregnancy. In our study majority of women had come for termination of pregnancy due to contraception failure (51\%). On further investigating the method used for contraception, these women reported of using abstinence or withdrawal method for contraception. It is long evident the high failure rates of natural methods of contraception. Next large subgroup was that of women having congenital anomaly in fetus (27\%). $12 \%$ had come with blighted ovum and $10 \%$ with sterilization failure.

Table 4: Methods used for evacuation.

\begin{tabular}{|lll|}
\hline $\begin{array}{l}\text { Methods used for } \\
\text { evacuation }\end{array}$ & Group A & Group B \\
\hline $\begin{array}{l}\text { Oxytocin drip/ } \\
\text { medical methods }\end{array}$ & 19 & 23 \\
\hline MVA & 31 & 39 \\
\hline S and E & 10 & 13 \\
\hline D and C & 21 & 25 \\
\hline $\begin{array}{l}\text { No intervention } \\
\text { required }\end{array}$ & 19 & - \\
\hline Total & 100 & 100 \\
\hline
\end{tabular}

Table 4 shows the methods used for evacuation of the contents of uterus. In $81 \%$ of cases of group A who presented as spontaneous abortion some medical or surgical intervention was needed so as to evacuate the uterus of the products of conception. 62 women underwent surgical evacuation of the uterine contents by various methods like MVA, Sand E and Dand C. in group B 23 women underwent termination by medical methods whilst, medical abortion kit, misoprostol alone or oxytocin in second trimester abortion. Medical abortion was usually preferred by primigravidas and young patients. MVA was preferred over D and $\mathrm{C}$ and $\mathrm{S}$ and $\mathrm{E}$.

Table 5: Distribution of cases according to repetition of procedure.

\begin{tabular}{|ll|}
\hline Procedure used & Group A and B \\
\hline Medical abortion & $\mathbf{7}$ \\
\hline D and C & 3 \\
\hline MVA & 2 \\
\hline Total & 12 \\
\hline
\end{tabular}

Table 5 shows that 12 women required repetition of procedure. Only surgical evacuation was employed for re evacuation. Re evacuation was most commonly followed in the women undergoing medical abortion in the first procedure. In our institution surgical evacuation is done under local anaesthesia and not under USG guidance. This being a blind procedure was equally followed by the repetition of procedure. 7 women in medical abortion group and 6 women in the surgical evacuation group required re evacuation. These were not significant statistically.

Table 6 compares the post abortion complications in the two groups. Minor and tolerable side effects were seen in the group that always remained under medical 
supervision, i.e., group B. Women in the spontaneous abortion group experienced major and even life threatening side effects. Heavy bleeding leading to severe anemia and requiring blood transfusion was seen in group A much more frequently ( $p$ value $=0.002$ ). These well correlated statistically, indicating these women often come in hypovolemic shock than when the termination is planned in advance. Septic abortion and hemorrhage were the cause of 2 mortalities in the study. Incidence of septicemia and post abortal pyrexia was also high in the group A. 10 women had pyrexia and 6 presented with foul smelling vaginal discharge $(p$ value $=0.008)$. These findings strongly correlated statistically. 1 patient required hysterectomy but oliguria was present in 6 women in the group A.

Table 6: Comparison of post-abortion complications.

\begin{tabular}{|c|c|c|c|c|}
\hline Complications & $\begin{array}{l}\text { Group A } \\
(\mathrm{n}=\mathbf{1 0 0})\end{array}$ & $\begin{array}{l}\text { Group B } \\
(\mathrm{n}=100)\end{array}$ & P value & Significance \\
\hline Gastrointestinal Side effects & 3 & 21 & 0.003 & Significant \\
\hline Heavy Bleeding & 56 & 30 & 0.002 & Significant \\
\hline Severe Anemia $(\mathrm{Hb}<6$ gm\%) & 38 & 15 & 0.002 & Significant \\
\hline Hypovolemic shock (Persistent SBP <80 mmHg) & 6 & - & 0.004 & Significant \\
\hline Required blood transfusion & 35 & 10 & 0.004 & Significant \\
\hline $\begin{array}{l}\text { Evidence of foreign body in vagina, cervix or } \\
\text { uterus }\end{array}$ & 0 & 0 & & \\
\hline Infection & 8 & 2 & 0.316 & Non-significant \\
\hline Pyrexia & 10 & 8 & 0.008 & Significant \\
\hline Foul smelling discharge & 6 & 2 & & \\
\hline RPOC & 23 & 8 & & \\
\hline $\begin{array}{l}\text { Uterine or adnexal tenderness when cervix was } \\
\text { moved }\end{array}$ & 1 & 0 & & \\
\hline Septicemia & 4 & 1 & 0.316 & Non-significant \\
\hline Generalized peritonitis/tetanus/Gangrenous uterus & 1 & 0 & 0.316 & Non-significant \\
\hline Major Trauma/Gut or bowel injury & 1 & 0 & 0.316 & Non-significant \\
\hline Hysterectomy & 1 & 0 & 0.316 & Non-significant \\
\hline Oliguria & 6 & 0 & 0.003 & Significant \\
\hline Cardiac arrest & 2 & 0 & 0.155 & Non-significant \\
\hline Mortality & 2 & 0 & 0.223 & Non-significant \\
\hline
\end{tabular}

Table 7: Post abortion contraception.

\begin{tabular}{|lll|}
\hline $\begin{array}{l}\text { Procedure } \\
\text { adopted }\end{array}$ & $\begin{array}{l}\text { Group A } \\
(\mathbf{n = 1 0 0})\end{array}$ & $\begin{array}{l}\text { Group B } \\
(\mathbf{n = 1 0 0})\end{array}$ \\
\hline Tubectomy & 20 & 22 \\
\hline Condom & 14 & 17 \\
\hline OCPs & 27 & 18 \\
\hline IUCD & 7 & 8 \\
\hline Did not opt any & 32 & 35 \\
\hline Total & 100 & 100 \\
\hline
\end{tabular}

Gastrointestinal side effects were higher in the group B. In contrast to 21 women having minor gastrointestinal side effects in group B, only 3 women had them in the group A. Major complications risking the life of the woman were less frequently found in the group B. There were neither mortalities nor serious side effects like septicemic shock, hypovolemic shock, bowel injury, oliguria, or cardiac arrest in the group B.
Table 7 depicts the method of post abortal contraception adopted by the women in each group. As high as $35 \%$ women did not opt for any contraceptive method. While the most common method for contraception employed in both groups were tubectomies. In group A $68 \%$ of women accepted post-abortion contraception (44\% $\mathrm{t}$ short-term methods like condoms or pills), $7 \%$ intrauterine devices [IUCDs], $20 \%$ sterilization). In group $\mathrm{B}, 65 \%$ of women accepted post-abortion contraception (35\% short-term methods like condoms or pills), $8 \%$ intrauterine devices [IUCDs], 22\% sterilization.

\section{DISCUSSION}

Unwanted pregnancies are a major burden on the health of a women and ultimately on nation. The liberated world gives the women the freedom to decide when she wants to conceive, by the use of innumerable methods of contraception, both temporary and permanent. But some others are either not aware of these contraceptives or are not fortunate enough to be able to use them. Even such a 
woman has the right to decide whether or not she wants to continue pregnancy. Septic and illegal abortion is one of the leading killers, esp. in developing countries like ours. An effort should be made to reduce this avoidable morbidity and mortality.

A study concluded by sample survey in NHFS revealed that around 6.4 million abortions are performed in India annually, of which 3.6 million (56\%) were unsafe. Latest data from government statistics on family welfare in India recorded 620472 abortions in 2010-11 at approved institutions. $1 / 3$ rd to $1 / 2$ nd of the woman have at least 1 induced abortion during their reproductive life. 1/3rd of their induced abortions are unsafe. $15 \%$ of maternal deaths are due to unsafe abortion, majority (90\%) of unsafe abortion are performed in developing countries. ${ }^{3}$

Woman need not die or suffer medical consequences from abortion because induced abortions do not kill women; it is unsafely performed abortions which causes mortality and morbidity. About $15 \%$ of all conceptions end in miscarriage. Out of these $80 \%$ are in $1^{\text {st }}$ trimester. The public health care system providing legal and safe abortions are concentrated in the urban areas while more than $60 \%$ of abortions occur in rural areas. Only 14-18\% of the PHC and community health centers actually provide abortion services. ${ }^{2}$ Our study was primarily in the area of a district place, hence such difference could not be appreciated. To reduce the mortality and morbidity associated with induced abortion MTP Act was liberalized in MTP act 1971. The 1st trimester MTP is associated with less complication than $2^{\text {nd }}$ trimester MTP. Many advances have taken place in methods of termination of pregnancy so evolution of MVA in $1^{\text {st }}$ trimester MTP resulted in high level of efficacy with simplicity and cost effectiveness.

In group A $16 \%$ are $<21$ years of age and $62 \%$ are between 21 and 30 years of age. In group B $20 \%$ are $<21$ years of age and $70 \%$ are between 21 and 30 years of age. In all groups maximum cases belonged to the age group of 18-25 yrs. Niinimäki et al, in his study found that each year approximately 11,000 induced abortions are performed in Finland, the majority of these women being younger than 25 years of age. ${ }^{4}$ Medical abortion with the antiprogestin mifepristone and the prostaglandin analogue misoprostol is increasingly being used instead of surgical method (dilatation of cervix and uterine evacuation with instruments). Higher fertility in young women make them also the at risk population to the complications of pregnancies.

In both the groups the women belonged to the multigravida group. In group A $70 \%$ women were multigravidas while in group B $76 \%$ women were multigravidas. So most of the women go for MTP after completing their family by 2 living children. In a study by Vineeta et al, the mean parity range was around $2.3+/-$ 0.45 in her study group. ${ }^{5}$ In group A out of 100 cases, 45 presented as incomplete abortion, 4 as threatened abortion, 20 as inevitable abortion, 12 as missed abortion and 19 with complete abortion. In our study majority of women had come for induced abortion due to contraception failure $(51 \%)$ and congenital anomaly of fetus $(27 \%) .12 \%$ had come with blighted ovum and $10 \%$ with sterilization failure. Inadequate knowledge of contraception and inaccessibility to the same are the main causes of unwanted pregnancies. In many religions using contraception is not permitted. These women resort to natural methods for contraception which have higher failure rates. Women then fall prey to an unwanted pregnancy which poses a financial as well as mental stress on the family.

In group A 33 cases had gestational age of 6-10 wks, 38 cases had 10-12 wks of gestational age and 18 cases had 12-14 wks of gestational age, 11 cases had gestational age of $>14$ wks. In group B 37 cases had gestational age of 6-10 wks, 31 cases had 10-12 wks of gestational age and 20 cases had 12-14 wks of gestational age, 12 cases had gestational age of $>14$ wks. In study of Suk et al, it was 9.5 wks and in study of Vineeta et al, it was 9.4 wks. ${ }^{5,6}$ So now-a-days women come earlier for induced abortion due to early diagnosis of pregnancy which is associated with less complication rate as complication rate increase with increase duration of pregnancy.

In group A 56 patients presented with heavy bleeding and 38 were severely anemic and 35 required blood transfusions. These complications were lesser in group B where 36 patients experienced heavy bleeding and 15 were severely anemic and 10 required blood transfusion. Patients with medical abortion mainly experienced gastrointestinal side effects. 2 mortalities were seen with multiple organ dysfunction (a case of septic abortion) and hemorrhagic shock being the cause of death. In a study conducted in Burdwan, West Bengal, of all the cases of abortion, septic abortion cases were $8.2 \%$. The most common clinical presentation was pallor $(88.8 \%)$ and fever $(86 \%){ }^{7}$ Case fatality rate was as high as $13.5 \%$ in this study. Patients in this study presented with foul smelling discharge, abdominal pain, shock, peritonitis, oliguria pelvic abscess. The wrongly attended or unattended cases of abortion lead to various complications like uterine injury, shock, injuries to gut or omentum, pelvic abscess, hepatic failure and septic thrombophlebitis. Similarly in our study also these complications could be seen but no statistical significance could be found due to the small sample size. In the study by Vineeta et al the complication pattern was almost the same, wherein main complication was bleeding and pain, with statistical significance $\mathrm{p}$ value $<0.001 .^{5}$ Surgical evacuation as a method for termination carries more life threatening risk with it. Perforation and incomplete abortion are other complications that need to be addressed while planning such procedures.

A register-based study of 56117 abortions by Weijin Zhou et al, concluded that side-effects in the form of bleeding, infections or re-evacuation were recorded for 
about $5 \% .^{8}$ We found more side-effects in teenage women and for abortions performed late in pregnancy.

Unmet needs are global, which look at issues as they relate to the family planning needs of its reproductive population in a quantifiable mode. In developing countries about half of sexually active women of reproductive age, or 818 million women, want to avoid pregnancy of which $17 \%$, or 140 million, are not using any method of family planning, while $9 \%$, or 75 million, are using less-effective traditional methods. Together, 215 million women are said to have an unmet need for modern contraception. ${ }^{9}$ According to NFHS - III (20052006) the overall unmet needs for family planning in India is about $13.2 \%$ and that in currently married rural women, $14.6 \%$. The NFHS-III also revealed that the unmet need was highest among women below age 20 years, the need was almost entirely for spacing rather than for limiting and was getting reduced with advancement of age. ${ }^{9}$ A prospective study in Madhya Pradesh, found that 278 (73\%) of 381 women had sought an abortion because they did not want a child at that time, suggesting a high unmet need for family planning. Another study revealed that Sterilization is the most popular method of contraception in India with a prevalence of $37 \%$ and accounts for $66 \%$ of all contraceptive use.

The Guttmacher institute in 2009 report that if all women who wanted to avoid pregnancy were using modern contraceptives, the number of unintended pregnancies in developing countries would fall from 75 million to 22 million annually. ${ }^{2}$ This would translate to 22 million fewer unplanned births, 15 million fewer unsafe abortions, and 90000 fewer maternal deaths. Family planning alone can prevent a quarter to a third of all maternal deaths saving 140000 to 150000 lives a year, worldwide.

The reach and approach of family planning methods and their segregation according to the safety must make a clear stand in the mind of each woman. A planned and supervised termination shall be less associated with complications and mortalities.

\section{CONCLUSION}

To every woman who has come to us for abortion, we should offer contraceptive care and improving their knowledge of the provision of contraceptive methods, including emergency contraception. It's an important step toward improving the reproductive health of women in
India. Comprehensive contraceptive counseling can help prevent unintended pregnancies that lead to abortions and should include information on when fertility returns after a birth or abortion; discussion of the full range of contraceptive methods and their characteristics, effectiveness and side effects; an assessment of a woman's characteristics, contraceptive needs and goals; and, if applicable, information about resupply. It is important that abortion services be seen not in isolation, but as part of a constellation of care tailored to the sexual and reproductive health needs of reproductive-age women.

\section{Funding: No funding sources}

Conflict of interest: None declared

Ethical approval: The study was approved by the Institutional Ethics Committee

\section{REFERENCES}

1. Government of India, Sample Registration System Statistical Report 2012, New Delhi: Office of the Registrar General, 2013.

2. Stillman M, Frost JJ, Singh S, Moore AM. Abortion in India: A Literature Review. Guttmacher Institute, December 2014.

3. International Institute for Population Sciences (IIPS) and Macro International, National Family Health Survey (NFHS), 2010-11, India, Mumbai: IIPS, 2012.

4. Niinimäki M1, Pouta A, Bloigu A, Gissler M, Hemminki E, Suhonen S. Immediate complications after medical compared with surgical termination of pregnancy. Obstet Gynecol. 2009;114(4):795-804.

5. Mohindra V, Sushil Kumar VSM. Vaginal misoprostol for first trimester pregnancy termination. J Obstet Gynecol India. 2005;55(4):358-60

6. Goldberg AB, Dean G, Kang MI. Manual versus electric vacuum aspiration for early first trimester abortion: A controlled study of complication rates. Obstetrics and gynecology. 2004;103:101-7.

7. Hazra SK, Sarkar PK, Chaudhuri A. Septic abortion managed in a tertiary hospital in West Bengal. Journal of basic and clinical reproductive sciences January- June 2013;2(1):38-41.

8. Zhou W, Nielsen GL. Short-term complications after surgically induced abortions: A register-based study of 56117 abortions. 2002. DOI: 10.1034/j.16000412.2002.810410.x

9. National Family Health Survey (NFHS-3), 20052006. India IIPS. 2007;1:1-535.

Cite this article as: Maru L, Verma M, Khan T.

Reinforcing the vast difference between the outcomes of spontaneous versus induced miscarriages. Int J Reprod Contracept Obstet Gynecol 2016;5:4031-6. 